\title{
A media strategy to spread sports awareness Among Egyptian university students
}

\author{
Mohamed Ahmed Al-Gazar \\ Specialist in the Media Center of Tanta University, \\ $\mathrm{PhD}$ researcher, Department of Sports Management and Recreation, \\ Faculty of Physical Education, Tanta University Egypt \\ algzaralgzar10@gmail.com
}

\begin{abstract}
The media in its various forms is one of the most important means used in the upbringing of the individual, as it contributes to the formation of personal trends and convictions, through the dissemination of news, programs and dialogues that link the individual to the concems and issues of his society. A media strategy through which sports awareness can be spread among Egyptian university students. This research paper also presents a number of suggestions and recommendations for spreading awareness of the importance of practicing sports activities among Egyptian university students.
\end{abstract}

Keywords: Media strategy - sports awareness - Egyptian university students - sports culture

\section{Introduction}

The media is all aspects of cognitive activities aimed at providing the public with all the news, facts and correct information, and discussing the most important contemporary problems and issues in an objective manner without distortion, which helps to reach the greatest level of knowledge, awareness and awareness, and to inform the public of everything that happens in their societies, which contributes to enlightening opinion public opinion and the formation of the correct opinion among all segments of society.(Cad al-Haq,2019)

During the previous years, the environment of sports media systems, especially with regard to the development and expansion of levels of sports competition and the increase in awareness of the importance of the actual practice of sports activities, witnessed a great development that depends primarily on the actual interest in the quality of the sports product and its quality and requirements to reach a distinguished and high quality sports industry.

In light of this, the sports decision-makers' interest in applying the concepts of strategic management and their contents to meet the needs of sports media, through extrapolating the future and developing strategic plans based on environmental analysis, including understanding and awareness of the factors of strength and weakness and identifying the most important opportunities and threats in line with the reality of the sports media organization (Charadaqa,2020).
Therefore, many thinkers in the field of developing media strategies believe that strategic planning is a thought and a behaviour, as it is an effective way to save any organization that seeks to achieve a competitive advantage in light of the economic, environmental, societal, organizational and administrative problems it faces.

\section{Study problem}

Through the work of the researcher, as a specialist at the media center at Tanta University, he noticed a lack of awareness and weakness in the level of sports awareness among a large number of students, not only at the level of Tanta University, but also at the level of a large number of Egyptian university students. This appears through the participation of Tanta University in festivals and summit meetings. Such as the (Egyptian Universities Youth Week), which is at the university level in the Arab Republic of Egypt. This is what called the researcher to try to use the media field in order to contribute to spreading sports awareness among students, through research and study to reach a media strategy to spread sports awareness among university students. Egyptian.

After reviewing a number of references, studies and specialized scientific periodicals that dealt with the issue of developing a media strategy to spread sports awareness among Egyptian university students - within the limits of the researcher's knowledge - he noticed that none of the researchers touched on research on this subject, despite the great importance and the message to 
which he contributes. The field of media and its great role in spreading spoits awareness among students

\section{Scientific addition to Study}

1) The scientific addition to the Study is due to the important role played by the mass media in spreading sports awareness among Egyptian university students.

2) This Study helps in developing a media strategy that contributes to spreading sports awareness among Egyptian university students.

3) The importance of this Study is due to its application to one of the most important sectors of the state that has a direct impact on comprehensive development, which is the Egyptian universities sector.

4) This Study contributes to spreading sports awareness among Egyptian university students in addition to providing students with many experiences, knowledge and life skills as they are the future human wealth of the nation.

A set of general characteristics for developing a media strategy that can achieve its objectives:

- The strategy must be non-routine in nature and always subject to change.

- The strategy must include all administrative levels and functional areas within the organization

- The strategy always expresses a conception and description of the basic features of the organization, and the nature of its interaction with the extemal environment with its different dimensions and levels.

- The strategy is not required to express longterm plans, but it can express medium and short-term plans.

\section{Media of University}

The university media is an integral part of the educational media, as it is a form of it, and it is a purposeful media message issued by academic institutions, characterized by accuracy and credibility, with the aim of introducing the university and enhancing its role and position in a way that contributes to achieving its goals and functions. (Batat,2019)

\section{Means and tasks of University Media}

Educational media play a major role in the process of teaching and leaming, whether it is inside the educational institution itself, such as what happens in schools, institutes and universities, or outside the educational institution, as happens through television, radio, cinema and others. Of which:

- E-portal

- Social networking sites

- Educational radio

- University newspapers

- Educational TV

- Educational blogs (Siraj,2019)

\section{Methodology:}

The most important features of the media strategy for spreading sports awareness among Fgyptian uni versity students:

There is a set of steps used in building the proposed strategy; most of the proposed strategies go according to the following steps:

1) Environmental analysis and diagnosis of the current situation: by analyzing the intemal environment with the aim of identifying strengths and weaknesses, as well as analyzing the extemal environment with the aim of identifying opportunities and threats. Strengths mean all the intemal capabilities that help to exploit opportunities and confront threats such as the existing advantages and positives, and weaknesses mean all the factors of deficiency, the interior that hinders the ability to exploit opportunities and always needs follow-up and evaluation.

2) Drafting the vision and mission: The vision is a description and formulation of the future that the institution aspires to reach and it is a future vision that defines what it hopes the position of the institution will be in the future.

3) Formulation of strategic objectives: Objectives are the objectives that we wish to reach in the future, and clearly defining objectives is the bas is for the success of the strategy, and objectives are formulated by focusing on and strengthening strengths and overcoming and eliminating weaknesses.

4) Determining the general principles on which the strategy is based: This strategy is based on the foundations and principles set by the new Sports Law (No. 71 of 2017). It is necessary to rely on the important principles and atticles contained in this law, primarily aimed at organizing all private matters, practicing all sports activities in the Arab Republic of Egypt.

5) Determining the axes of the strategic plan: The cument strategy is divided into two main axes:

- The first axis: the role of educational institutions in spreading sports awareness.

- The second axis: the role of the media in spreading sports awareness

6) Implementation stage: The stage of implementing the media strategy to spread sports awareness among Egyptian university students requires the establishment of an accredited national media centre that follows the Egyptian Council of Ministers and includes all ministries, whether they are (the Ministry of Education, the Ministry of Higher Education or the Ministry of Youth and Sports), and its primary objective is the process of dissemination Correct sports awareness among Egyptian university students, through planning, coordination, follow-up and evaluation of all sports programs and activities provided to students in order to encourage them to practice sports activities of all kinds within Egyptian universities. Specialists in this field, in addition to 
representatives from the Ministry of Higher Education and Scientific Study, the Ministry of Education and the Ministry of Information, in addition to a number of media professionals who have a great public tumout so that this centre will be a link between govemmental and non-govemmental organizations in order to reach an important goal, which is the process of spreading sports awareness in Egyptian society in general and for Egyptian university students in particular.

7) Follow-up and evaluation stage: The follow-up and evaluation stage is one of the most important stages of implementing the strategy, where a team is formed to follow up on the implementation of the strategic plan and work on evaluating it, leading to its evaluation according to agreed standards and performance measures, and evaluating the difference between the current situation and the target situation, as through evaluation it is possible to enter Some modifications to the strategic plan according to new changes.

\section{Steps to implement the Study plan}

- Theoretical readings of scientific references and studies related to the Study topic.

- Designing the Study questionnaire.

- Suggesting the hypothetical axes of the questionnaire form

- Presenting the virtual axes to the experts.

- Suggest a number of phrases for each axis of the initial questionnaire.

- Presenting the questionnaire to the experts.

- Drafting the final form of the questionnaire.

- Apply the questionnaire in its final form

- Emptying the data of the questionnaire.

- Presentation and discussion of the results.

- Reaching conclusions and recommendations.

\section{Procedures}

The Researcher used the descriptive approach us ing survey studies as one of its pattems, due to its relevance to the nature and objectives of the Study

\section{Community}

The Study community represents administrators and supervisors of sports activities in Egyptian universities, directors of student care in public administrations in Egyptian universities, and supervisors of sports activities in the Egyptian Universities Sports Federation.

\section{The Study sample}

A sample selected of (140) examined from the supervisors of sports activities in Egyptian universities, directors of student care in Egyptian universities, and supervisors of sports activities in the Egyptian Universities Sports Federation.

They were divided into (20) examinees to find the scientific transactions "veracity and reliability" of the questionnaire under Study, and (20) examinees to conduct the survey study, and the number (100) examined to conduct the final application of the questionnaire under Study, which dealt with developing a media strategy to spread sports awareness among Egyptian university students.

\section{Results}

Through Study, the Researcher reached some important results, including:

1. There are no departments in Egyptian universities specialized in spreading sports awareness among students.

2. There are no clear goals and specific and objective criteria through which to develop a media strategy for spreading sports awareness among Egyptian university students.

3. Students do not participate in developing plans and programs for practicing sports activities among Egyptian university students.

4. A large number of supervisors in charge of implementing sports activities in Egyptian universities are not specialized in this field, and they did not receive specialized training courses.

5. The plans organizing sports activities in Egyptian universities do not include awareness activities aimed at spreading sports awareness among students.

6. There is no financial budget aimed at spreading sports awareness among Egyptian university students from the Ministry of Youth and Sports.

7. There is no financial budget aimed at spreading sports awareness among Egyptian university students from the Universities Sports Federation.

\section{Recommendation}

We are recommended the following:

1) department specialized in spreading sports awareness among Egyptian university students should be created.

2) There must be clear goals and specific and objective criteria for setting the media strategy for spreading sports awareness among Egyptian university students.

3) Students should participate in developing plans and programs for practicing sports activities among Egyptian university students.

4) set of training courses for qualifying and training supervisors responsible for sports activities in Egyptian universities should be implemented.

5) The plans organizing sports activities in Egyptian univers ities must include awareness activities aimed at spreading sports awareness among students.

6) Communication and coordination with the Ministry of Youth and Sports to provide financialbudgets aimed at spreading awareness among Egyptian university students.

7) Communication and coordination with the Egyptian Universities Sports Federation to provide financial budgets aimed at spreading awareness among students. 


\section{References}

[1] Al-Atafi, Samir Magdy Ahmed. (2019). Evaluation of sports activity resources in student welfare departments in the faculties of Mansoura University. Master's thesis, Faculty of Physical Education, Mansoura University.

[2] Al-Nader, Haitham Awad .(2020). An analytical study of the level of sports awareness among students of Al-Balqa Applied University in Jordan, published scientific Study, An-Najah University Journal for Study. An-Najah National University.

[3] Arab, bin Musli. (2019). Media coverage of sports topics in the written press and their relationship to citizenship values from the point of view of students of sciences and techniques of physical and sports activities, Ph.D. thesis, Algeria, Mohamed Boudiaf University in M'sila, Institute of Science and Techniques of Physical and Movement Activities.

[4] Batat, Noureddine, .(2019). The role of sports media in disseminating sports culture among students of science and technology of physical and sports activities. Published scientific Study, Al-Tahadi Journal, University of Larbi Ben Mhidi, Institute of Sciences and Techniques of Physical and Sports Activities.

[5] Charadaqa, Tahseen Anis .(2020). A proposed strategy for the development of media colleges in the Arab world in the light of contemporary transformations. published scientific Study, Journal of Human and Society Sciences.

[6] Gad al-Haq, Samah Muhammad .(2020). The effect of a web-based educational media program on developing intellectual security for undergraduate students. PhD thesis, Faculty of Specific Education, Mansoura University.

[7] Hegazy, Islam Muhammad. (2019). Factors associated with sports awareness among students of the Arab Academy for Science and Technology. published scientific Study, the Scientific Journal of Sports Science and Arts, Helwan University, Faculty of Physical Education for Girls.

[8] Shodar, Bilal Mahmoud. (2020). The role of Facebook in spreading sports awareness among secondary school student. a field study on a sample of 454 secondary school students, Shahid Ghailassa. Master's thesis, Mohamed Boudiaf University of M'sila, Institute of Sciences and Techniques of Physical and Sports Activities.

[9] Siraj, Sobhi Mohamed. (2019). A proposed strategy for investing recreational activities in light of the marketing gaps in the sports facility in Kafr ElSheikh Governorate.The Scientific Journal of Physical Education and Sports Sciences, Faculty of Physical Education, Mansoura University.

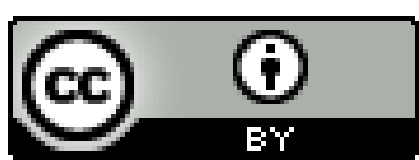

